\title{
Role of Eosinophils in Inflammatory Bowel and Gastrointestinal Diseases
}

\author{
Samantha A. Woodruff, Joanne C. Masterson, Sophie Fillon, \\ Zachary D. Robinson, and Glenn T. Furuta
}

\begin{abstract}
Inflammatory bowel diseases (IBD) are characterized by the invasion of leukocytes into the intestinal mucosa. However, a mixed inflammatory picture is observed that includes neutrophils, lymphocytes, monocytes, and eosinophils. To this day, the role of eosinophils in health and in disease remains unclear. Investigations into their function stem primarily from allergic diseases, asthma, and parasitic infections. This makes it even more difficult to discern a role for the fascinating eosinophil in IBDs because, unlike the lung or the skin, eosinophils reside in normal intestinal mucosa and increase in disease states; consequently, an intricate system must regulate their migration and numbers. These granulocytes are equipped with the machinery to participate in gastrointestinal (GI) inflammation and in the susceptible microenvironment, they may initiate or perpetuate an inflammatory response. A significant body of literature characterizes eosinophils present in the GI microenvironment where they have the potential to interact with other resident cells, thus promoting intestinal remodeling, mucus production, epithelial barrier, cytokine production, angiogenesis, and neuropeptide release. A number of lines of evidence support both potential beneficial and deleterious roles of eosinophils in the gut. Although studies from the gut and other mucosal organs suggest eosinophils affect mucosal GI inflammation, definitive roles for eosinophils in IBDs await discovery.
\end{abstract}

Key Words: Crohn disease, eosinophil, inflammatory bowel disease, ulcerative colitis

(JPGN 2011;52: 650-661)

$\mathrm{E}$ nigmatic eosinophils continue to intrigue clinicians and scientists alike. Although their presence in mucosal microenvironments traditionally characterizes allergic diseases, their role in other diseases (rheumatologic, infectious, idiopathic inflammatory) remains unknown. Equally confounding is that, unlike the lung or skin, eosinophils normally reside in intestinal mucosa, suggesting that they play a role in gastrointestinal (GI) health. Despite this knowledge, advancement on the understanding of their exact role in GI health and disease remains limited. With this in mind, we review basic, translational, and clinical studies that focus on proposed

Received November 30, 2010; accepted January 26, 2011.

From the Digestive Health Institute, Gastrointestinal Eosinophilic Diseases Program, Section of Pediatric Gastroenterology, Hepatology and Nutrition, The Children's Hospital, Denver, CO.

Address correspondence and reprint requests to Glenn T. Furuta, 13123 East 16th Ave, B290, Aurora, CO 80045 (e-mail: furuta.glenn@tchden. org).

Samantha A. Woodruff and Joanne C. Masterson participated equally in this study.

The authors report no conflicts of interest.

Copyright (1) 2011 by European Society for Pediatric Gastroenterology, Hepatology, and Nutrition and North American Society for Pediatric Gastroenterology, Hepatology, and Nutrition

DOI: $10.1097 / \mathrm{MPG} .0 \mathrm{~b} 013 \mathrm{e} 3182128512$ functions of eosinophils in the intestinal mucosa, provide an overview of eosinophil trafficking, and speculate as to the role of these intriguing cells in the intestinal microenvironment as they relate to inflammatory bowel diseases (IBDs).

\section{ARE EOSINOPHILS EQUIPPED WITH MACHINERY TO PARTICIPATE IN GI INFLAMMATION?}

Eosinophils are armed with the ability to synthesize and release a number of molecules that reflect their potential physiological diversity and biological influence (Table 1). In the susceptible microenvironment, they may initiate or perpetuate an inflammatory response.

\section{Granule Proteins}

Eosinophils are best identified by their abundance of granular proteins, also referred to as eosinophil-derived granule proteins (EDGPs). There are at least 5 proteins secreted from the eosinophil granule including eosinophil peroxidase (EPO), eosinophilic cationic protein (ECP), eosinophil-derived neurotoxin (EDN; eosinophil protein X, or EPX), major basic protein (MBP), and CharcotLeyden crystal protein. MBP is one of the most abundant proteins produced by eosinophils, and is found as 2 different homologues (MBP1 and MBP2). MBP1 is also produced at much lower levels in basophils; however, MBP2 is eosinophil specific $(1,2)$. ECP and EDN are both ribonucleases and both function to protect the host from infections, mainly, it is thought, through pore formation in pathogens $(3-5)$. EPO is $68 \%$ homologous to its neutrophil counterpart myeloperoxidase and functions similarly in antimicrobial or antiviral roles in addition to contributing to superoxide production $(6,7)$. Charcot-Leyden crystal is found in both eosinophils and basophils (8); however, traditionally it has been associated with conditions characterized by eosinophilia, including asthma, allergies, and parasite infection. Indeed in the 1970s, the presence of EDGPs following eosinophil degranulation was predominantly noted at sites of parasitic infection and was thought to represent evidence of antiparasitic activity. These highly charged cationic proteins create pores in cellular membranes resulting in parasite death and host protection $(9,10)$. In mice, increases in parasite burden following thoracic filarial parasitic infection was observed in strains deficient in either EPO or MBP granule proteins (11); however, human EPO deficiency is a rarely reported finding and has no known clinically associated symptoms (12). Thus, eosinophils were thought to act in a protective manner, defending the host from invading pathogens and potential disease.

Although early studies suggested that extracellular deposition of EDGPs represented an important host defense mechanism, present-day studies have also focused on the contribution of EDGPs and other eosinophil-derived factors to disease pathogenesis and 
TABLE 1. Eosinophil-derived products with potential targets of action

Eosinophil products

Target cells

IL-3, IL-5, GM-CSF, eotaxins, EDGPs

$\mathrm{T}_{\mathrm{H}} 1$ : IL-2, IL-6, IL-12, TNF- $\alpha$, IFN- $\gamma$

$\mathrm{T}_{\mathrm{H}}$ 2: IL-2, IL,4 IL-5, IL-10, IL-13, leukotrienes

IL-1, IL-3, IL-4, IL-5, IL-9, IL-13, TNF- $\alpha$, GM-CSF, leukotrienes, prostaglandins, EDGPs

IL-1, IL-4, IL-5, IL-6, IL-13, TGF- $\beta$, GM-CSF, leukotrienes, eotaxins, EDGPs

IL-1, IL-6, TGF- $\beta$, leukotrienes, eotaxins, EDGPs

Eotaxins, neurotrophic growth factors, substance P, EDGPs

IL-1, IL-5, IL-13, TGF- $\beta$, leukotrienes, eotaxins, EDGPs

IL-1, IL-4, IL-13, TGF- $\beta$, eotaxins, EDGPs

TGF- $\alpha$
Autocrine eosinophil activity

Lymphocytes

Mast cells

Epithelial cells

Endothelial cells

Neurons

Smooth muscle cells

Fibroblasts

Goblet cells

EDGP $=$ eosinophil-derived granule protein; GM-CSF $=$ granulocyte macrophage-colony-stimulating factor; $I F N=$ interferon; $I L=$ interleukin; $\mathrm{TGF}=$ transforming growth factor; $\mathrm{T}_{\mathrm{H}}=\mathrm{T}$ helper cell; $\mathrm{TNF}=$ tumor necrosis factor.

chronicity, often in the absence of known pathogenic infection. Extensive eosinophil degranulation is often associated with fibrosis in hypereosinophilic syndrome, eosinophilic esophagitis (EoE), IBDs, asthma, and eczema (13-16). EDGPs are known to activate inflammatory mediator release from basophils and mast cells (1719). Bischoff et al (20) identified the altered presence of eosinophils and mast cell degranulation products in a morphometric study of patients with IBD compared with normal controls.

\section{Cytokines}

Eosinophils are classically associated with a T helper 2 cell $\left(\mathrm{T}_{\mathrm{H}} 2\right)$ cytokine profile including interleukin (IL)-4, IL-5, IL-10, and IL-13 (Table 1). IL-5 is critical for eosinophil growth, chemotaxis, and activation, whereas synergistic functions between eotaxin and IL-13 or eotaxin and IL-5 act as an eosinophil chemoattractant mechanism supporting a role for perpetuating eosinophilic inflammation $(21,22)$. Their ability to produce this classical repertoire of $\mathrm{T}_{\mathrm{H}} 2$ cytokines supports their role in allergic-type responses. In this regard, eosinophils express a number of cytokine receptors on their surfaces (23) and, therefore, may respond to their local microenvironment. Autocrine activities of IL-3 and granulocyte macrophage-colony-stimulating factor (GM-CSF) on tissue residing eosinophils suggest that they may play an autoregulatory role in which eosinophils could control their own maturation and antiapoptotic mechanisms during disease processes. These cytokines in addition to IL-5 promote eosinophil survival following recruitment to inflamed sites.

In contrast to this association with $\mathrm{T}_{\mathrm{H}} 2$-cytokine-mediated diseases, eosinophils also have the capacity to synthesize and secrete $\mathrm{T}_{\mathrm{H}} 1$ cytokines in both health and disease (24). Tumor necrosis factor-alpha (TNF- $\alpha$ ), the key cytokine in Crohn disease (CD), has been associated with recruitment of eosinophils in IBD (25). Interestingly and in contrast to their roles in other cell types, activation of the TNF receptor 1 and TNF-related apoptosis-inducing ligand in eosinophils is associated with prolonged eosinophil survival $(26,27)$.

The $\mathrm{T}_{\mathrm{H}} 2$ cytokine IL-13 is a pivotal player driving the major pathologies associated with asthma, regulating eosinophil recruitment (chemokine induction), mucus secretion (cell differentiation), and airway hyperresponsiveness (smooth muscle activation) (28). During appropriate inflammatory conditions eosinophils produce functional IL-13 protein (29). Eosinophils are also potent sources of the immunoregulatory, profibrotic cytokine transforming growth factor- $\beta$ (TGF- $\beta)$. TGF- $\beta$ is implicated in tissue remodeling in various diseases including pulmonary and esophageal diseases (30). TGF- $\beta$ is the prototypical ligand for the TGF superfamily of cytokines and growth factors. This family of growth factors is implicated in various downstream functions including control of proliferation and differentiation processes, inflammation, and, most notably, fibrosis. Eosinophils also secrete the anti-inflammatory agents IL-10 and indoleamine 2,3-dioxygenase, all important mediators for the immunoregulation of proinflammatory $\mathrm{T}_{\mathrm{H}} 1$-cell activity. Although a strong case for the proinflammatory role of eosinophils exists, there is a growing body of evidence to support a potential regulatory role for eosinophils in mucosal microenvironments (31). For instance, in certain murine allergic pulmonary models, eosinophils are required for the recruitment of effector $T$ cells and the resulting pulmonary pathology associated with murine ovalbumin (OVA)-induced airway hyperresponsiveness $(32,33)$. Jacobsen et al elegantly demonstrated the necessity for pulmonary eosinophilia for the successful recruitment of effector $T$ cells and for the establishment of a $\mathrm{T}_{\mathrm{H}} 2$ cytokine environment in this murine pulmonary allergy model (33). In a murine model of Schistosoma egg induction of $\mathrm{T}_{\mathrm{H}}$ 2-associated inflammation, Sabin et al (34) demonstrated the necessity for eosinophils in the early production of the $\mathrm{T}_{\mathrm{H}}$ 2-driving cytokine IL-4. In the absence of eosinophil recruitment mediated by mast cells and IL-5, there is an ablation of this critical IL4 production. The role of eosinophils in antiparasitic immunity remains under investigation. A number of infection models in mice chemically or genetically deficient in eosinophil responses found no specific role for the eosinophil (23). In IBD, research suggests an association between elevated eosinophil activation and relapsing disease activity, whereas others suggest a reparative role as eosinophil levels rise during the remission of intestinal inflammation $(25,35)$. Eosinophils also produce potentially anti-inflammatory agents such as arylsulfatase B, histaminases, and phospholipase D, adding to this suggestion (23).

In addition to cytokines, eosinophils secrete chemokines such as eotaxins, RANTES, and macrophage inflammatory protein- $\alpha$ (MIP-1 $\alpha)(5,36)$ (Table 1). Eotaxins $(-1,-2,-3)$ are potent eosinophil chemoattractants, and their secretion by eosinophils demonstrates their ability to initiate/perpetuate an inflammatory response (37). Eotaxin attracts eosinophils via interaction with the $\mathrm{C}-\mathrm{C}$ chemokine receptor 3 (CCR3) receptor, which is expressed almost exclusively by eosinophils $(38,39)$. RANTES stimulates both eosinophil and neutrophil recruitment (40). In contrast, MIP-1 $\alpha$ is important primarily in neutrophil trafficking (41). Thus, eosinophils secrete chemokines involved in their own recruitment, as well as in other leukocyte recruitment and activation. In this light, eosinophils play an important role in mediating the establishment 
and maintenance of the local immune microenvironment following activation.

\section{Lipid Mediators}

Eosinophils secrete lipid mediators including leukotrienes and platelet-activating factor. In addition, eosinophils express receptors for leukotrienes and prostaglandins (Table 1). These products are generally considered proinflammatory because they increase leukocyte trafficking, endothelial adhesion, smooth muscle contraction, vascular permeability, and mucus secretion (5). The role of lipid mediators in asthma and allergic inflammation has been well defined as they cause bronchoconstriction, mucus hypersecretion, and bronchial hyperresponsiveness. Vieira-de-Abreu et al (42) demonstrated increased in vivo formation of lipid bodies and leukotrienes within infiltrating eosinophils in a mouse model of asthma.

\section{HOW DO EOSINOPHILS TRAVEL TO GI MUCOSAL SURFACES?}

Because eosinophils normally reside in the GI tract and increase in disease states, an intricate system must regulate their migration and numbers.

\section{Growth and Development}

Hematopoietic stem cells differentiate into myeloid lineagespecific progenitor cells, which give rise to a common precursor cell of both basophil and eosinophil cells in the bone marrow. Eosinophil specification is regulated in this common precursor cell by the control of transcription factors GATA-1, PU.1, and c/EBP. IL-3, IL-5, and GM-CSF play important roles in the development of eosinophils. Eosinophil progenitor cells express the cytokinespecific alpha receptors for each of these cytokines along with the beta-receptor unit shared by all 3. Under the influence of these cytokines in concert with temporal regulation of the transcription factors mentioned above, eosinophils mature and are ready for exit from the bone marrow. The IL-5 cytokine is the most specific of these eosinophilopoietins for eosinophil development, and its actions are essential for the migration of eosinophils into the bloodstream, where they reside for approximately 1 week (5). Mice deficient in IL-5 lack appropriate eosinophil responses during inflammatory states with deficiency in mounting robust eosinophil responses $(43,44)$, whereas transgenic mice engineered to overproduce IL-5 have profound eosinophilia (45). However, other cells are also equipped to respond to this cytokine. Detailed descriptions of the eosinophil life cycle are available (5).

\section{Migration to Intestinal Mucosa}

\section{Eosinophil Migration to Intestinal Mucosal Surfaces}

Under normal conditions, the vast majority of eosinophils reside in the GI mucosa, and during disease states, these levels increase (5). Understanding signals that drive intestinal eosinophilia is particularly important because unlike the lung and skin, eosinophils are normal inhabitants of the GI mucosa. Mechanistic studies elucidating how eosinophils home to GI surfaces have focused on the role of eotaxin and IL-5. Eotaxin null mice lack intestinal and thymic eosinophils, whereas the induction of allergic airway disease in these mice results in a diminished pulmonary eosinophilia $(46,47)$.

Eosinophils express specific adhesion molecules that allow for their migration out of the periphery and across the endothelium in response to chemoattractants such as eotaxins- a process known as extravasation. This extravasation process is mediated by similar molecules and processes that mediate all leukocyte migration, rolling, adhesion, and transmigration. The exact mechanisms by which eosinophils are recruited to areas of inflammation are beginning to be unraveled. Tissue specificity for eosinophil recruitment is thought to be mediated by the various chemokines, selectins, integrins, and adhesion molecules and their receptors, both on the eosinophil and on the vascular endothelium. Expression of these molecules may be controlled in a microenvironmentally specific manner. For example, Brandt et al (48) found an essential role for $\beta 7$-integrin in the recruitment of eosinophils to small intestinal inflammation, but found no role for this integrin's expression for eosinophil recruitment to the lung.

Eosinophils constitutively express L-selectin and, in addition, use both E- and P-selectin machinery to slow down and tether to endothelial cells (49-51). P-selectin glycoprotein ligand (PSGL-1) and sialyl-Lewis $\mathrm{x}$, the ligands for endothelial $\mathrm{E}$ - and P-selectin, are expressed on eosinophils (52). The recruitment of eosinophils toward peritoneal ragweed sensitization and challenge models in mice deficient in L-, E-, or P-selectin or deficient in combinations of these selectins found a role for each of these molecules in eosinophil adhesion to the endothelium. The authors of this work pointed to a particularly important role for P-selectin. However, they also highlighted the potential for other nonselectin-dependent mechanisms of eosinophil recruitment resulting from the continued recruitment of eosinophils in mice deficient in all 3 selectins (53). Indeed, dextran sodium sulfate (DSS) colitis induced in L-selectin-specific-deficient mice revealed no role for this selectin in this model of acute large intestinal inflammation (54).

Once tethered to the cytokine-activated endothelium, eosinophils roll, spread, and transmigrate between endothelial cells and across the endothelial basement membrane. There, eosinophils make their way through the extracellular matrix to the source of the original chemotaxin and respond to inflammation by potential activation and degranulation. This migration process is controlled by integrins and their receptive endothelial or matrix protein receptors. Eosinophils have overlapping recruitment pathways to mast cells, and basophils, however, distinctively express a large number of adhesion molecules and receptors that specifically control their transmigration, namely $\alpha 3, \alpha 4, \alpha 5, \alpha 6, \alpha \mathrm{D}, \alpha \mathrm{L}$, $\alpha \mathrm{M}, \alpha \mathrm{X}$, and $\beta 1, \beta 2$, and $\beta 7$ integrins (55). Eosinophils, in addition, express certain cell adhesion molecules (CAMs) that bind these integrins. Very late antigen (VLA-4) and lymphocyte functionassociated antigen (LFA-1) on the eosinophil surface interact with endothelial vascular cell adhesion molecule (VCAM-1) and intercellular adhesion molecule 1 (ICAM-1) in a process regulated by eotaxins. Inhibition of these ligands disrupts the migration of eosinophils into the tissue in experimental models and clinical trials, emphasizing their importance as components in the eosinophil inflammatory response $(21,56)$.

Brandt et al and Forbes et al identified specific adhesion molecules necessary for eosinophil recruitment to the small and large intestinal mucosa. Small intestinal eosinophil recruitment relies on MadCAM-1/ $\alpha 4 \beta 7$ integrin interactions; however, colonic eosinophil migration relies on $\beta 2$ integrin molecules $(48,54,57)$. For instance, $\beta 7$-integrin knockout mice developed less small bowel inflammation compared with wild-type controls in a model of allergic disease (48). Mice exhibited increased circulating eosinophils, indicating no role for this integrin in bone marrow exit and vascular entry. This deficiency is only apparent during inflammation because there is no baseline deficiency in eosinophil presence in the small intestine during homeostasis in $\beta 7$-integrin-deficient mice. Another method of tissue-specific homing of eosinophils involves the differential regulation of the chemokines 
C-C chemokine ligand 25 (CCL25) (TECK) in the small intestine and CCL28 (MEC) in the large intestine $(40,58)$. The receptors for these chemokines, CCR9 and CCR3, have been demonstrated on the surface of eosinophils, as has the eosinophil responsiveness in culture conditions $(59,60)$.

Using ICAM-1 null mice and ICAM neutralizing antibodies in a DSS colitis model, Forbes et al (54) demonstrated the $\beta 2$ integrin/ICAM-1 dependency of colonic eosinophilic inflammation. In contrast, DSS colitis in a $\beta 7$-integrin knockout mouse and mice treated with $\alpha 4$-integrin inhibitory antibodies showed no change in the level of eosinophil recruitment to the colon.

Eosinophils use VLA-4 ( $\alpha 4 \beta 1)$ and VLA-6 $(\alpha 6 \beta 1)$ to interact with basement membrane and extracellular matrix proteins, such as laminin, collagen, and fibronectin to traverse the basement membrane and travel through the lamina propria $(61,62)$. This binding leads to eosinophil priming, and following exposure to inflammatory cytokines, eosinophils become activated and may degranulate upon appropriate stimulation. In the absence of these tissue-recruitment signals or the lack of survival signals such as GM-CSF, IL-5, or TNF, eosinophils will undergo apoptosis (21).

Taken together, these findings suggest a variety of regulatory mechanisms for the different GI microenvironments that may ultimately affect future therapeutic interventions.

\section{Esophageal Mucosa}

Normal esophageal mucosa does not contain eosinophils. Eosinophils increase in squamous epithelia of the esophageal mucosa during gastroesophageal reflux disease (GERD) and EoE, but the characteristic numbers and associated histological features of each disease are only now being addressed. For instance, GERD is traditionally associated with a small number of eosinophils in the distal squamous epithelial surface, but recent evidence demonstrates that large numbers ( $>15$ eosinophils/hpf) can be found in both the proximal and distal epithelium of children and adults with GERD $(63,64)$. During the last decade, an emerging body of evidence shows that eosinophils also increase in EoE (65). EoE is a clinicopathological disease characterized by upper intestinal symptoms seen in association with $>15$ eosinophils/hpf in which GERD and other diseases have been ruled out. Gastric and duodenal biopsies must also be normal.

The mechanisms leading to esophageal eosinophilia have been addressed in several human genetic studies together with a number of murine models. An important study of human esophageal biopsies by Blanchard et al (66) identified a unique transcript signature that reliably identified patients with EoE. Of these genes, eotaxin 3 was the most upregulated gene. Further studies confirmed this association and identified IL-13 as a potent regulator of eotaxin 3 in esophageal biopsies and isolated epithelial cells (67). Thus, these studies define a role for eotaxin 3 in certain patients with EoE. A more recent study (68) of genome-wide associations identified a link between certain patients with EoE and variants at the $5 \mathrm{q} 22$ loci. This and future studies will help elucidate the mechanisms by which eosinophils are recruited in individuals and may provide more guidance in the management of this disease.

Mice sensitized to and challenged with the ubiquitous aeroallergen, Aspergillus fumigatus, develop significant IL-5-dependent esophageal eosinophilia $(69,70)$. Intratracheal administration of IL13 promotes eosinophil recruitment to the esophagus in mice; however, this recruitment is ablated in mice genetically deficient in IL-5 (71). Pretreatment with an IL-13-blocking antibody effectively diminished eosinophilia in the same model system (72). Recently published work has additionally pointed to the indoor allergens, house dust mite and cockroach antigens, as potent inducers of experimental eosophageal eosinophilia. In the present study, authors indicate an increase in IL-4 and IL-13 in response to antigen exposure, whereas administration of antigen to Eotaxin $1 / 2$ double knockout, CCR3 - or IL-5-deficient mice abrogated eosinophil recruitment, indicating an essential role for these molecules in this allergen-induced model of esophageal eosinophilia (73). Together, these studies suggest that an exogenous allergen leads to esophageal eosinophilia that is dependent on $\mathrm{T}_{\mathrm{H}}$ 2-type cytokines, IL-4, IL-5, and IL-13. Despite these studies indicating the essential role for IL-5 in murine models, recent open-label trials using anti-IL-5 therapies were found to be effective in only a small number of patients $(74,75)$.

\section{Gastric, Small Intestinal, and Colonic Mucosa}

Eosinophils localize to the GI tract during perinatal development in an eotaxin- and IL-5-dependent manner (22). Whereas eosinophils are present in the lamina propria of wild-type, 19-dayold mouse embryos, their numbers in intestinal mucosa are significantly diminished in IL-5-deficient mice and eotaxin-deficient mice (22). Interestingly, the same study found no difference in the homeostatic levels of eosinophils in jejunal tissue of GM-CSFdeficient mice. Further investigation found no difference in the number of eosinophils in the bone marrow but decreased levels in circulation, indicating a critical role for these cytokines in exit of eosinophils from the bone marrow. Epithelial overexpression of IL5 and eotaxin leads to significantly increased numbers of intestinal eosinophils compared with control mice (57). In contrast, studies in isolated eotaxin deficiency show an absence of eosinophils in the intestine, even in the presence of high levels of IL-5, maintaining the essential role for eotaxins in the recruitment of eosinophils into the GI tract $(22,57)$. Finally, mice sensitized by intraperitoneal injection with OVA and later challenged with orally administered OVA develop significant eosinophilic GI inflammation. However, mice deficient in eotaxin under the same conditions have impaired eosinophil recruitment to intestinal tissues and are protected from weight loss and gastromegaly (76). All of these results further support the critical role of IL-5 in the development of eosinophils in the bone marrow; however, tissue eosinophilia is dependent on eotaxin. Thus, these proteins work in concert to induce an efficient eosinophil response in appropriate conditions.

\section{WHAT ARE THE FUNCTIONAL ROLES OF EOSINOPHILS?}

A number of lines of evidence support both potential beneficial and deleterious roles for eosinophils in the gut (Fig. 1).

\section{Potential Beneficial Aspects of Eosinophilia}

Eosinophils likely benefit human health, but at the present time, these roles are still speculative. Circumstantial evidence for a supportive role stems from their phylogeny that dates back to chordates. Eosinophils are present in normal mammalian mucosa, and genes encoding EDGPs are evolutionarily conserved between numerous species. Interestingly, eosinophils accumulate primarily at body surfaces that border the external environment, such as the GI mucosa, supporting a potential role in host defense (77).

\section{Antiparasitic}

Eosinophils have been classically described as antiparasitic leukocytes. Peripheral eosinophilia increases during helminth infection and eosinophils migrate to areas of parasitic infection with terminal endpoints of degranulation at sites of parasitic infiltration $(10,78)$. Epidemiological studies correlate peripheral eosinophilia 


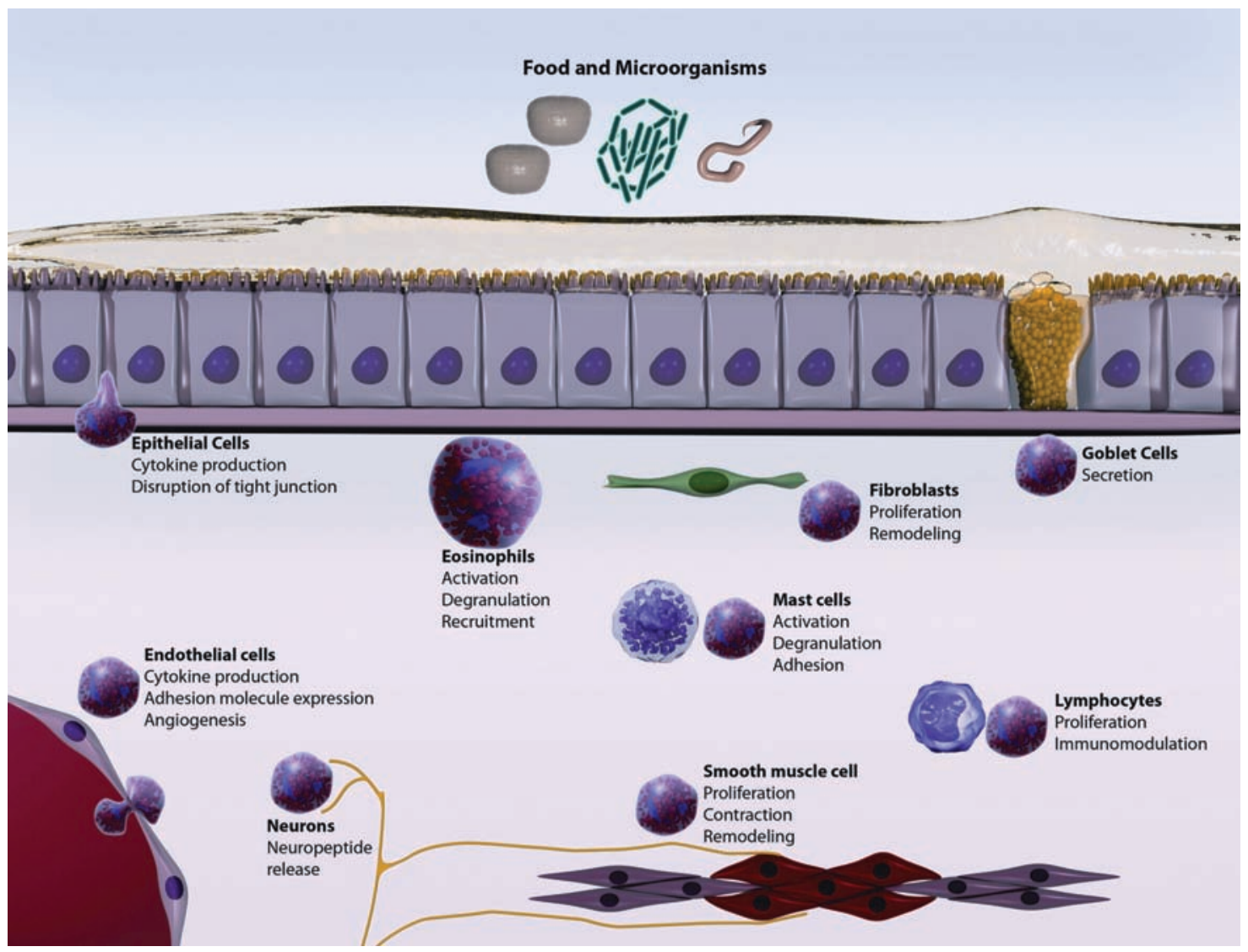

FIGURE 1. Proposed roles for eosinophils within the intestinal mucosa. Based on basic, translational, and clinical studies derived from other organs and the gastrointestinal tract, this figure presents potential mechanisms for eosinophils to interact with resident intestinal cells. Each of these complex and dynamic relationships is described in detail in the body of this review.

with protection against schistosomal infections in Africa. Proposed mechanisms for this response include the ability of EDGPs to induce cell membrane pore formation and mediate antibody- and/or complement-dependent cellular toxicity to parasites (79).

Despite these studies that suggest a role for eosinophils in helminth infection, data from murine models are less certain. Reduction of IL-5, either by genetic manipulation or by antibody depletion, leads to diminished eosinophilia and, in certain infections, more severe parasitic infection compared with mice that have a full complement of eosinophils. For example, IL-5 null mice infected with the nematode Strongyloides ratti show increased worm burden, tissue damage, and parasite fecundity. However, infection with the trematode Fasciola hepatica does not lead to phenotypic differences in IL-5 null mice compared with wild type $(79,80)$. In addition, mice depleted of eosinophils with the use of anti-IL-5 antibody do not show alterations in Trichinella infection compared with untreated mice (81). Finally, IL-5 transgenic mice with marked eosinophilia have no protection from Trichinella spiralis infection (82). It is likely that these differences can be attributed to redundancy of effector immune responses to specific pathogens and differences in the animal model that was used (80).

\section{Role in Cancer}

Recent studies suggest that, in some circumstances, eosinophils possess antineoplastic properties. For instance, eosinophils are associated with necrotic areas of tumors and within the tumor pseudocapsules. Peripheral eosinophilia is associated with improved prognosis in GI and head and neck cancers, but a poorer prognosis in oral squamous cell carcinoma. Certain forms of human cancer treatments that include cytokines IL-2, IL-4, and GM-CSF promote eosinophilia (83).

Murine studies support a role for eosinophils in decreasing tumor burden. For instance, in a murine model of cancer, malignant cells were transfected to constitutively overproduce IL-4. This leads to tissue eosinophilia at the site of tumors, decreased tumor burden, and improved survival (84). In another murine model, melanoma cells were transfected to express ovalbumin and injected into mice. OVA-specific $\mathrm{T}_{\mathrm{H}} 1$ or $\mathrm{T}_{\mathrm{H}} 2$ cells were generated and injected into the mice, and lung metastases were measured 18 to 20 days after tumor challenge. Lung metastases regressed in the mice injected with $\mathrm{T}_{\mathrm{H}} 2$ but not $\mathrm{T}_{\mathrm{H}} 1 \mathrm{CD} 4+$ cells. Regression of lung metastases was associated with the influx of eosinophils into the tumor sites, and degranulating eosinophils were detected at regressing tumor sites. Eosinophil recruitment and tumor regression was not noted in eotaxin-deficient mice, implicating eotaxin as a key molecule in the recruitment of eosinophils to tumor sites (85). In mice completely void of eosinophils, fibrosarcoma tumor burden is significantly enhanced (86). Finally, recent speculation suggests that eosinophils can respond and traffic to damage-associated molecular pattern molecules (83).

In contrast, eosinophils may promote the growth of certain tumors. For instance, in a hamster model of squamous cell 
carcinoma, the administration of anti-IL-5 antibody completely obliterated tumor-associated tissue eosinophilia and subsequently decreased tumor burden and delayed the onset of cancer development (87).

\section{Antiviral}

As previously noted, eosinophil granule proteins demonstrate antiviral activities. ECP and EDN are ribonucleases with antiviral activity (88). Eosinophils express Toll-like receptors (TLR)-3, TLR-7, and TLR-9, which recognize dsRNA, ssRNA, and dsDNA, respectively $(89,90)$. Activation of the TLRs generates interferon-beta, thus initiating antiviral host responses (4). Also, in a murine model of respiratory syncytial virus (RSV) infection, IL-5 transgenic mice that harbor profound peripheral eosinophilia show accelerated virus clearance and decreased airway hyperreactivity (4). Transfer of eosinophils, but not IL-5 alone, into RSV-infected wild-type mice leads to accelerated viral clearance and diminished airway hyperreactivity supporting eosinophil specificity of this response. Finally, eosinophil-deficient mice have significantly delayed RSV clearance (4).

\section{Antibacterial}

Traditional studies of innate effector cells providing immunity to bacteria have focused on the roles of neutrophils and macrophages. The contribution of eosinophils has been understudied and overlooked. Lehrer et al (91) provided early evidence for the antibacterial role of the eosinophil granule proteins ECP and MBP in vitro. However, 2 recent publications have rehighlighted the potential importance of eosinophils in challenging bacterial infections. Mice deficient in eosinophils had a significant increase in the colony-forming units of Pseudomonas aeruginosa bacteria following infection of mouse peritoneal cavities, and the induction of Pseudomonas peritonitis. This bacterial burden was abrogated in mice transgenically engineered to have profound eosinophilia (IL-5 transgenic mice) or in mice treated with eosinophil granules following infection (92). Yousefi et al (93) described a previously undetected process by which eosinophils release their mitochondrial DNA in a catapult-like fashion, without subsequent death of the eosinophil, which leads to extracellular bacterial death. This release was detected in response to lipopolysaccharide from Gramnegative bacteria and showed successful killing of Escherichia coli in a DNA-dependent fashion in vitro. In support of this antibacterial role for eosinophils, in vivo studies using the mouse bacterial intestinal infection model cecal ligation puncture in mice with high levels of eosinophilia (IL-5 transgenic) found significant improvement in survival and significant reduction in circulating bacterial burden. Although these studies call attention to the beneficial role of eosinophils in fighting bacterial infections, early reports suggested a reduction in circulating eosinophils during the acute phase in bacterial infections in patients (94). It, however, remains possible that eosinophils have been recruited to the tissue site of infection and may not be detectable in the circulation. This has never been systematically studied, thus leaving unanswered the etiology of this reduction and the role of the eosinophil in these infections.

\section{Antigen Presentation}

Wang et al (95) provide evidence supporting the eosinophil's role in antigen presentation. Isolated splenic eosinophils, free from antigen-presenting cells, were cultured with GM-CSF and shown to express major histocompatibility complex class II and other costimulatory molecules. Eosinophils were then incubated with
OVA and transferred into the lung intratracheally. Exposure of eosinophils to OVA-specific CD4+ T cells led to eosinophil proliferation, cytokine secretion, and cell surface activation. These studies provide supportive evidence that eosinophils may process antigen in the lung lumen and function as antigen-presenting cells to CD4+ lymphocytes (95). In another study, Shi et al (96) provided morphological evidence of this process. Following airway challenge, eosinophils were isolated from the airways or the peritoneal cavities of IL-5 transgenic mice and fluorescently labeled ex vivo. Labeled cells were reinstilled into the trachea and were found to home to lymph nodes in an eotaxin-independent manner. Labeled eosinophils expressed major histocompatibility complex class II and co-stimulatory CD80 and CD86 proteins and functioned in vitro as CD80- and CD86-dependent, antigen-specific, antigen-presenting cells.

\section{Innate Mechanisms of Defense}

A potential mechanism for eosinophils to protect against microbial invasion is through the stimulation of mucus production. In the lung, eosinophils are associated with induction of mucus production. Exposure of human airway epithelial cells to supernatants derived from activated eosinophils leads to increased mucin production through eosinophil release of TGF- $\alpha$ and activation of epidermal growth factor receptor (EGFR) (97). Rhinopulmonary epithelia associated with mucosal eosinophils have goblet cell hyperplasia and metaplasia, indicative of accelerated mucus production (98). Finally, in OVA-induced airway eosinophilic inflammation, use of gefinitib, an EGFR inhibitor, or CCR3 monoclonal antibody reduced eosinophil recruitment to the murine lung and mucus production $(99,100)$.

\section{Potential Deleterious Aspects of Eosinophilia}

Eosinophils also have been implicated as pathogenic effector cells in asthma, atopy, eczema, infection (viral, bacterial, or parasitic), malignancy, EoE, GERD, IBD, allergic colitis of infancy, celiac disease, vasculitis, connective tissue diseases, and hypereosinophilic syndrome as reviewed previously (101). Much evidence supporting a pathological role for eosinophils is derived from morphological and association studies in which eosinophils and their products are present in diseased tissue. Below we highlight the potential pathogenic interactions of eosinophils with resident and recruited cells of mucosal surfaces (Fig. 1).

\section{Epithelium}

Eosinophils are the predominant inflammatory cells found in the airway epithelium in asthma. Bronchoalveolar lavage fluid from asthmatics contains increased numbers of eosinophils and levels of MBP. Early studies have shown MBP to be toxic to lung epithelia, leading to increased airway epithelial permeability in vitro. Although other eosinophil products are known to promote epithelial proliferation (102), Pegorier et al (103) demonstrated that lung epithelial cells exposed in culture to MBP or EPO showed a significant increase in TGF- $\alpha$, TGF- $\beta 1$, EGFR, platelet-derived growth factor- $\beta$, and tenascin mRNA levels.

\section{Smooth Muscle Cells, Fibroblasts, and Nerves}

The application of MBP to airway smooth muscle leads to contraction and enhancement of muscle reactivity to acetylcholine and histamine, findings that may explain the contribution of eosinophils to airway hyperreactivity $(5,56)$. Ablation of IL-5 in murine models of asthma leads to decreased eosinophil recruitment to the 
airway, attenuated airway hyperreactivity, and diminished lung damage (44). The most compelling evidence implicating eosinophils in the pathogenesis of asthma comes from the PHIL mouse, a genetically engineered mouse that lacks eosinophils. Airway resistance after methacholine challenge is significantly diminished in PHIL compared with wild type, supporting a role for eosinophils in airway dysfunction (104).

Eosinophils may also participate in tissue remodeling. For example, ex vivo modeling of the human airway revealed that the addition of activated eosinophils to a matrix of fibroblasts and bronchial epithelial cells leads to a significant increase in epithelial thickness (102). Gomes et al (14) revealed that coculture of eosinophils with fibroblasts induces fibroblast IL-6 and fibronectin production. In further studies, eosinophil-derived IL- $1 \alpha$ and TGF- $\beta$ were shown to participate in this response, thus promoting a role for eosinophils in modulating extracellular matrices. Studies examining esophageal biopsies from patients with EoE associate eosinophils with tissue remodeling (30). At endoscopy, some patients with EoE demonstrate evidence of remodeling and fibrosis with the presence of isolated strictures, long segment narrowing, or esophageal fragility $(16,105)$. Histological staining of the affected subepithelial layer from patients with EoE reveals increased collagen deposition and increased TGF- $\beta$ expression compared with patients with GERD and healthy controls $(16,30)$. One of the complexities of intestinal eosinophilia is the lack of reliable clinical outcome measures. Although a number of studies provide circumstantial evidence for a role of eosinophils in esophageal remodeling and fibrosis, the correlation of fibrosis, eosinophilia, and symptoms remains variable.

Eosinophils have direct cell-to-cell contact with both airway neurons in asthma (106) and damaged neurons of the GI tract in IBD $(76,106,107)$; however, the meaning of this interaction remains uncertain. Kingham et al (108) demonstrated that upon coculture with eosinophils, guinea pig parasympathetic nerves undergo dosedependent shortening. In addition, neuron differentiation is inhibited by eosinophils or MBP in a dose-dependent manner. Eosinophils may also alter nerve remodeling. MBP induced M2 muscarinic receptor expression on cholinergic nerves and reduction in intracellular acetylcholine content in vitro (109). A recent review by Raap and Wardlaw (110) rehighlighted the reciprocal interactions between eosinophils and peripheral nerve cells. In this review they emphasize a number of neuromediator receptors functionally expressed on eosinophils leading to cytokine and granule protein release. The effects of granule proteins on neuron function and viability are addressed (eg, the in vitro neurotoxic activities of EDN and ECP). In addition, the potential indirect interactions between neuropeptides, mast cells, and eosinophils are discussed.

\section{Mast Cells}

A number of groups have characterized the influence of eosinophils and EDGPs on mast cells. Zheutlin et al (111) showed that rat mast cells significantly increase histamine release in response to MBP and ECP, but not EDN. MBP induced histamine release, arachidonic acid synthesis, and TNF- $\alpha$ release from murine mast cells with a connective tissue phenotype (112). In contrast, Okayama et al (113) showed that MBP, EPO, EDN, and ECP do not stimulate histamine release from cultured human skin mast cells. Taken together, these studies emphasize the complex and variable role eosinophils may play on mast cell function depending on the microenvironment.

\section{DO EOSINOPHILS PLAY A ROLE IN IBD?}

GI tissues affected by IBD demonstrate evidence of mucosal eosinophilia. Although studies from the gut and other mucosal organs suggest that eosinophils affect mucosal GI inflammation, definitive roles for eosinophils in IBD await discovery. Figure 1 demonstrates the potential interactions of the eosinophil with the intestinal mucosa and its resident cells.

\section{Histological Characterization}

To date, eosinophils are implicated in IBD because of their morphological association with the diseased tissue. Early studies of mucosal biopsies from patients with IBDs revealed that eosinophils were prominent leukocytes infiltrating the intestinal epithelia (114117) (Fig. 1). Because of this initial observation, ulcerative colitis (UC) and CD were sometimes described as allergic diseases (118). A complicating factor in determining whether mucosal eosinophilia is pathological is the fact that normal values for GI eosinophilia, distal to the esophagus, have yet to be established. DeBrosse et al (119) retrospectively characterized the quantity and distribution of eosinophils in 28 children. They measured a wide variation from a maximum of 26 eosinophils/hpf in the small intestine to up to 50 eosinophils/hpf in the proximal colon.

Accumulation of eosinophils in IBD has been characterized in a number of histological studies; however, accuracy in true reflection of the numbers and the contribution of eosinophils have been hampered by various factors including use of nonspecific staining, low sample numbers, sample acquisition, and choice of patient population (120). Whereas some studies relied on hematoxylin and eosin staining for eosinophil identification, others were powered with sample sizes as low as 2 per group in some instances. In fact, recent evidence points to the importance of examination of granular protein content in inflamed tissues because examination of hematoxylin and eosin staining alone overlooks the contribution of degranulated eosinophil products in diseased tissues (121). However, taken together, these studies indicate an increase in the numbers of mucosal eosinophils in patients with IBD.

Recent studies characterized mucosal eosinophilia in the colon and associated increased mucosal eosinophilia with IBD. Pensabene et al evaluated the clinical significance of colonic eosinophilia in 69 children seen during an 18-month period. Diagnostic categories included IBD (32\%), irritable bowel syndrome $(33 \%)$, and food allergies $(10 \%)$, with the remainder receiving a wide range of other diagnoses. The distinguishing features for IBD included high lamina propria cellularity and intracryptal/intraepithelial eosinophils (122).

\section{Secreted Eosinophil Products}

Whereas some studies have characterized tissue eosinophilic inflammation in IBD, others have focused on measuring secreted products from eosinophils in the blood, tissue, intestinal lumen, and fecal samples. Because it is well known that eosinophils secrete a number of eosinophil-specific granule proteins such as ECP, EPO, $\mathrm{EDN}$, and MBP, increased levels of these products provide further circumstantial support for their role in IBD. Peripheral eosinophils from patients with active IBD have increased ECP release compared with those with treated quiescent disease. These findings are consistent with similar studies in asthma; patients treated with prednisone have diminished ECP release and IL-5 expression compared with those with active disease (123).

Ultrastructural studies demonstrate that eosinophils release granule products in tissues with IBD. Some of the earliest studies in this regard focus on electron microscopic studies of colonic resection specimens from patients with $C D$, which identified numerous eosinophils, extracellular eosinophil MBP granule deposition, and cytotoxic tissue changes $(10,124)$. Other studies $(125,126)$ 
examining mucosal biopsies from patients with $\mathrm{CD}$ reveal increased eosinophils and ECP, and EPO deposition in visually inflamed and normal areas of colon. Dubucquoi et al (127) showed increased mucosal eosinophilia and IL-5 in the resected colon of patients with $\mathrm{CD}$ requiring ileocolectomy. This increase in mucosal eosinophils and IL-5 expression in the neoileum was associated with endoscopic recurrence of disease at surveillance endoscopy 3 months later, suggesting that eosinophilia and local IL-5 production was associated with early mucosal damage in CD.

Multiple groups have analyzed the concentration of EDGPs in stool and correlated increased EDGP concentrations with severity of disease. Berstad et al (128) first identified increased levels of fecal ECP in stool samples from active ulcerative colitis (UC) compared with normal, uninflamed controls. Bischoff et al (129) later confirmed these findings in measurements of increased ECP and EPX in stool samples from patients with UC, CD, and food allergy compared with controls. They noted higher concentrations of stool ECP and EPX in patients with evidence of gross mucosal inflammation at endoscopy. Saitoh et al (130) found significantly elevated concentrations of fecal levels of ECP and EPX in active $\mathrm{UC}$ and $\mathrm{CD}$ compared with clinical and endoscopically inactive UC and CD. Both inactive and active IBD had higher levels of ECP and EPX compared with healthy controls. Also, inactive patients with IBD with higher ECP and EPX fecal levels were more likely to relapse in the following 3 months. Finally, Peterson et al (131) studied fecal EPX levels in patients with UC with endoscopically active disease before and after treatment. They determined that fecal EPX decreased after corticosteroid treatments.

Colonic perfusion fluids from patients with intestinal inflammation also contain increased levels of EDGPs compared with controls. For example, Carlson et al (132) found elevated ECP, $\mathrm{EPO}$, and EPX in colonic perfusion fluids of patients with colitis and isolated proctitis compared with healthy controls. They later found that colonic perfusion levels of ECP, EPO, and EPX decreased following steroid treatment (35). Sangfelt et al (35) found that a reduction of EDGP levels in rectal perfusion fluid was associated with successful response to prednisone treatment in patients with EGIDs. Increased ECP levels in colonic perfusion effluents in children with UC and CD (133) and adults with UC (134) have also been described.

In contrast, Heatley and James (135) analyzed rectal biopsies from patients with UC undergoing surveillance colonoscopy. They found that patients with mild-to-moderate disease who had responded to treatment had significantly raised tissue eosinophil counts compared with patients with aggressive disease that did not respond to treatment. The authors speculated that eosinophils may have contributed to the positive clinical response. Similarly, Lampinen et al (25) found increased eosinophil activation, as defined by CD69 and CD44 staining, in UC in remission compared with active $\mathrm{UC}$, and suggested that eosinophils may contribute to repair of injured epithelia. Finally, Troncone et al (133) found increased ECP levels in gut lavage fluid in children with UC and CD, compared with healthy controls, but ECP levels did not directly correlate with clinical disease activity scores.

Raab et al (136) found a significant elevation in levels of the lipid prostaglandin E2 (PGE2) in rectal and sigmoid perfusates in patients with UC. Increased levels were associated with elevations in ECP, MPO, and TNF- $\alpha$ levels. These mediators were colocalized with eosinophils and macrophages, implicating these 2 cell types in the synthesis of PGE2 in colitis. PGE2 has multiple functions including potential roles in intestinal repair; further studies will define the role of eosinophil-derived lipid mediators in protection against or participation in mucosal injury in IBD (137).

Patients with active IBD present with significant elevation in serum levels of eotaxin when compared with patients with quiescent disease or normal controls, indicating a potential role for eotaxin and its downstream targets in IBD activity $(38,39)$. Other authors found elevated levels of activated eosinophils in pediatric UC. This eosinophilia was determined to positively correlate with disease severity and predominantly resulted from eotaxin-1 production in rectosigmoid colonic specimens (138). Eosinophil recruitment and activation may play an important role in the chronicity of IBD in patients.

Taken together, these studies focus on microscopic evidence of eosinophilia, eosinophil degranulation, cytokine production, and increased eosinophil granule protein products in the stool and colonic perfusion fluid of patients with severe UC or CD. They suggest that the eosinophil is associated with IBD-in other words, present and active at the site of inflammation.

\section{Deleterious Impact of Eosinophil Products on the GI Tract}

Guilt by association is not enough to convict the eosinophil as a participant in the pathogenesis of IBD. As described above, a number of clinical and translational studies have shown that eosinophils and their products are increased in tissues affected by IBD and bathe mucosal surfaces at the sites of inflammation. Thus, studies focusing on eosinophils and their products in reductionist and genetically modified murine systems are beginning to tease out the role of this leukocyte. In a reductionist noncontact, coculture model system examining the impact of eosinophils on colonic epithelial cells, eosinophil-derived products were shown to diminish epithelial barrier function as measured by transepithelial resistance. The active soluble product derived from this coculture system was identified as MBP, whereas EDN did not elicit the same impact (139). $\mathrm{Xu}$ et al (15) demonstrated that sonicates from eosinophils increase fibroblast proliferation and collagen production in fibroblasts outgrown from biopsies in active CD. A comparative study of peripheral eosinophils between patients with $\mathrm{CD}$ and UC indicates differences in chemotactic abilities, adhesion properties, and degranulation activity between these patient subsets (140). Thus, the eosinophil may indeed present in a variety of phenotypes depending on the immune environment and associated disease mechanism.

Several animal models show the eosinophil's impact as an effector cell in models of IBD. For example, MBP null mice exposed to oxazolone colitis were relatively protected from colitis compared with wild-type mice, suggesting a role for MBP (139). Forbes et al (141) also showed that in the murine model of DSS colitis, mice have increased colonic eosinophilia, GI dysfunction, and release of EPO into the colonic lumen. Eotaxin knockout mice have decreased colonic eosinophilia, attenuated experimental UC, and decreased levels of colonic EPO release $(54,138)$. EPOdeficient mice have attenuated experimental colitis, providing further support for the eosinophil's role (141). Shichijo et al (142) examined EDGPs in a rat model of UC. Rats treated with anti-ECP antibody develop attenuated DSS colitis, decreased ECP staining, and improved epithelial healing compared with untreated controls. Finally, Ahrens et al and Vieira et al $(138,143)$ both have shown that mice congenitally deficient in eosinophil development are protected from experimental colitis.

SAMP1/Yit mice develop spontaneous ileitis in association with increased IL-5 and eosinophil infiltration (144). Anti-IL-5 antibody treatment in a model where severe combined immunodeficiency mice are recipients of naïve and effector CD4+ cells from the SAMP1/Yit mouse leads to improvement of ileitis, colitis, and eosinophil infiltration (144). In another study, when IL-5 knockout mice, which have decreased eosinophils at a baseline, undergo DSS colitis no changes in disease severity were seen compared with wild-type controls (43). Thus, although human data remain circumstantial, both cell culture and animal models are providing 
increasing evidence for a role for eosinophils and their granule proteins in the pathogenesis of intestinal inflammation. A growing body of literature now exists that examine specific roles of eosinophilia in colitis in genetically engineered mice that are deficient in eosinophil-specific granule proteins, eosinophils, or eosinophil chemokines (eotaxin). Further basic and translational research into the specific mechanisms by which eosinophils participate in intestinal inflammation is still needed.

\section{CONCLUSIONS}

Circumstantial evidence places eosinophils at the scene of inflammation. A growing body of basic evidence in other organs, including the gut, implicates eosinophil products with tissue dysfunction. Is the eosinophil the purveyor of tissue damage? Is the eosinophil, the innocent bystander, attacked in the fray along with the intestinal epithelium? Was the eosinophil recruited for tissue repair at the site of damage?

Considering the published literature that examines the gut as well as other organs, it is reasonable to speculate a beneficial and deleterious role for eosinophils in IBDs. Eosinophils are present in healthy intestinal mucosa and increase during inflammation. They possess an armamentarium of biologically active mediators that, in the appropriate microenvironment, may help or harm the host. Although the bulk of evidence supports a pathological role for eosinophils in IBDs, recent microbial studies support a protective role in states of sepsis. Reductionist in vitro experiments, relevant animal models, and translational studies will continue to shed light on this intriguing cell for many years to come.

\section{REFERENCES}

1. Ackerman SJ, Kephart GM, Habermann TM, et al. Localization of eosinophil granule major basic protein in human basophils. J Exp Med 1983;158:946-61.

2. Plager DA, Loegering DA, Checkel JL, et al. Major basic protein homolog (MBP2): a specific human eosinophil marker. J Immunol 2006; 177:7340-5.

3. Slifman NR, Loegering DA, McKean DJ, et al. Ribonuclease activity associated with human eosinophil-derived neurotoxin and eosinophil cationic protein. J Immunol 1986;137:2913-7.

4. Phipps S, Lam CE, Mahalingam S, et al. Eosinophils contribute to innate antiviral immunity and promote clearance of respiratory syncytial virus. Blood 2007;110:1578-86.

5. Rothenberg ME, Hogan SP. The eosinophil. Annu Rev Immunol 2006; 24:147-74.

6. Petrides PE. Molecular genetics of peroxidase deficiency. J Mol Med 1998;76:688-98.

7. Klebanoff SJ. Myeloperoxidase: friend and foe. J Leukoc Biol 2005; 77:598-625.

8. Ackerman SJ, Weil GJ, Gleich GJ. Formation of Charcot-Leyden crystals by human basophils. J Exp Med 1982;155:1597-609.

9. Gleich GJ, Frigas E, Loegering DA, et al. Cytotoxic properties of the eosinophil major basic protein. J Immunol 1979;123:2925-7.

10. Dvorak AM. Ultrastructural evidence for release of major basic protein-containing crystalline cores of eosinophil granules in vivo: cytotoxic potential in Crohn's disease. J Immunol 1980;125:460-2.

11. Specht S, Saeftel M, Arndt M, et al. Lack of eosinophil peroxidase or major basic protein impairs defense against murine filarial infection. Infect Immun 2006;74:5236-43.

12. Nakagawa T, Ikemoto T, Takeuchi T, et al. Eosinophilic peroxidase deficiency: identification of a point mutation (D648N) and prediction of structural changes. Hum Mutat 2001;17:235-6.

13. Ogbogu PU, Rosing DR, Horne MK 3rd. Cardiovascular manifestations of hypereosinophilic syndromes. Immunol Allergy Clin North Am 2007;27:457-75.

14. Gomes I, Mathur SK, Espenshade BM, et al. Eosinophil-fibroblast interactions induce fibroblast IL-6 secretion and extracellular matrix gene expression: implications in fibrogenesis. J Allergy Clin Immunol 2005;116:796-804.
15. Xu X, Rivkind A, Pikarsky A, et al. Mast cells and eosinophils have a potential profibrogenic role in Crohn disease. Scand J Gastroenterol 2004;39:440-7.

16. Chehade M, Sampson HA, Morotti RA, et al. Esophageal subepithelial fibrosis in children with eosinophilic esophagitis. J Pediatr Gastroenterol Nutr 2007;45:319-28.

17. Piliponsky AM, Gleich GJ, Nagler A, et al. Non-IgE-dependent activation of human lung- and cord blood-derived mast cells is induced by eosinophil major basic protein and modulated by the membrane form of stem cell factor. Blood 2003;101:1898-904.

18. O'Donnell MC, Ackerman SJ, Gleich GJ, et al. Activation of basophil and mast cell histamine release by eosinophil granule major basic protein. J Exp Med 1983;157:1981-91.

19. Patella V, de Crescenzo G, Marino I, et al. Eosinophil granule proteins activate human heart mast cells. J Immunol 1996;157:1219-25.

20. Bischoff SC, Wedemeyer J, Herrmann A, et al. Quantitative assessment of intestinal eosinophils and mast cells in inflammatory bowel disease. Histopathology 1996;28:1-13.

21. Rosenberg HF, Phipps S, Foster PS. Eosinophil trafficking in allergy and asthma. J Allergy Clin Immunol 2007;119:1303-10.

22. Mishra A, Hogan SP, Lee JJ, et al. Fundamental signals that regulate eosinophil homing to the gastrointestinal tract. J Clin Invest 1999;103:1719-27.

23. Hogan SP, Rosenberg HF, Moqbel R, et al. Eosinophils: biological properties and role in health and disease. Clin Exp Allergy 2008; 38:709-50.

24. Woerly G, Roger N, Loiseau S, et al. Expression of Th1 and Th2 immunoregulatory cytokines by human eosinophils. Int Arch Allergy Immunol 1999;118:95-7.

25. Lampinen M, Carlson M, Sangfelt P, et al. IL-5 and TNF-alpha participate in recruitment of eosinophils to intestinal mucosa in ulcerative colitis. Dig Dis Sci 2001;46:2004-9.

26. Tsukahara K, Nakao A, Hiraguri M, et al. Tumor necrosis factor-alpha mediates antiapoptotic signals partially via 338 MAP kinase activation in human eosinophils. Int Arch Allergy Immunol 1999;120 (Suppl 1): 54-9.

27. Robertson NM, Zangrilli JG, Steplewski A, et al. Differential expression of TRAIL and TRAIL receptors in allergic asthmatics following segmental antigen challenge: evidence for a role of TRAIL in eosinophil survival. J Immunol 2002;169:5986-96.

28. Kasaian MT, Miller DK. IL-13 as a therapeutic target for respiratory disease. Biochem Pharmacol 2008;76:147-55.

29. Schmid-Grendelmeier P, Altznauer F, Fischer B, et al. Eosinophils express functional IL-13 in eosinophilic inflammatory diseases. J Immunol 2002;169:1021-7.

30. Aceves SS, Newbury RO, Dohil R, et al. Esophageal remodeling in pediatric eosinophilic esophagitis. J Allergy Clin Immunol 2007;119: 206-12.

31. Jacobsen EA, Taranova AG, Lee NA, et al. Eosinophils: singularly destructive effector cells or purveyors of immunoregulation? J Allergy Clin Immunol 2007;119:1313-20.

32. Shen HH, Ochkur SI, McGarry MP, et al. A causative relationship exists between eosinophils and the development of allergic pulmonary pathologies in the mouse. J Immunol 2003;170:3296-305.

33. Jacobsen EA, Ochkur SI, Pero RS, et al. Allergic pulmonary inflammation in mice is dependent on eosinophil-induced recruitment of effector T cells. J Exp Med 2008;205:699-710.

34. Sabin EA, Kopf MA, Pearce EJ. Schistosoma mansoni egg-induced early IL-4 production is dependent upon IL-5 and eosinophils. $J$ Exp Med 1996; $184: 1871-8$.

35. Sangfelt P, Carlson M, Thorn M, et al. Neutrophil and eosinophil granule proteins as markers of response to local prednisolone treatment in distal ulcerative colitis and proctitis. Am J Gastroenterol 2001; 96:1085-90.

36. Bandeira-Melo C, Weller PF. Eosinophils and cysteinyl leukotrienes. Prostaglandins Leukot Essent Fatty Acids 2003;69:135-43.

37. Garcia-Zepeda EA, Rothenberg ME, Ownbey RT, et al. Human eotaxin is a specific chemoattractant for eosinophil cells and provides a new mechanism to explain tissue eosinophilia. Nat Med 1996;2:449-56.

38. Chen W, Paulus B, Shu D, et al. Increased serum levels of eotaxin in patients with inflammatory bowel disease. Scand J Gastroenterol 2001;36:515-20. 
39. Mir A, Minguez M, Tatay J, et al. Elevated serum eotaxin levels in patients with inflammatory bowel disease. Am J Gastroenterol 2002;97:1452-7.

40. Pan J, Kunkel EJ, Gosslar U, et al. A novel chemokine ligand for CCR10 and CCR3 expressed by epithelial cells in mucosal tissues. J Immunol 2000;165:2943-9.

41. Ottonello L, Montecucco F, Bertolotto M, et al. CCL3 (MIP-1alpha) induces in vitro migration of GM-CSF-primed human neutrophils via CCR5-dependent activation of ERK 1/2. Cell Signal 2005;17:355-63.

42. Vieira-de-Abreu A, Assis EF, Gomes GS, et al. Allergic challengeelicited lipid bodies compartmentalize in vivo leukotriene $\mathrm{C} 4$ synthesis within eosinophils. Am J Respir Cell Mol Biol 2005;33:254-61.

43. Stevceva L, Pavli P, Husband A, et al. Eosinophilia is attenuated in experimental colitis induced in IL-5 deficient mice. Genes Immun 2000;1:213-8.

44. Foster PS, Hogan SP, Ramsay AJ, et al. Interleukin 5 deficiency abolishes eosinophilia, airways hyperreactivity, and lung damage in a mouse asthma model. J Exp Med 1996;183:195-201.

45. Dent LA, Strath M, Mellor AL, et al. Eosinophilia in transgenic mice expressing interleukin 5. J Exp Med 1990;172:1425-31.

46. Matthews AN, Friend DS, Zimmermann N, et al. Eotaxin is required for the baseline level of tissue eosinophils. Proc Natl Acad Sci U S A 1998;95:6273-8.

47. Rothenberg ME. Eotaxin. An essential mediator of eosinophil trafficking into mucosal tissues. Am J Respir Cell Mol Biol 1999; 21:291-5.

48. Brandt EB, Zimmermann N, Muntel EE, et al. The alpha4bbeta7integrin is dynamically expressed on murine eosinophils and involved in eosinophil trafficking to the intestine. Clin Exp Allergy 2006; 36:543-53.

49. Kyan-Aung U, Haskard DO, Poston RN, et al. Endothelial leukocyte adhesion molecule- 1 and intercellular adhesion molecule- 1 mediate the adhesion of eosinophils to endothelial cells in vitro and are expressed by endothelium in allergic cutaneous inflammation in vivo. J Immunol 1991;146:521-8.

50. Georas SN, Liu MC, Newman W, et al. Altered adhesion molecule expression and endothelial cell activation accompany the recruitment of human granulocytes to the lung after segmental antigen challenge. Am J Respir Cell Mol Biol 1992;7:261-9.

51. Patel KD. Eosinophil tethering to interleukin-4-activated endothelial cells requires both $\mathrm{P}$-selectin and vascular cell adhesion molecule-1. Blood 1998;92:3904-11.

52. Symon FA, Lawrence MB, Williamson ML, et al. Functional and structural characterization of the eosinophil P-selectin ligand. J Immunol 1996;157:1711-9.

53. Robinson SD, Frenette PS, Rayburn H, et al. Multiple, targeted deficiencies in selectins reveal a predominant role for P-selectin in leukocyte recruitment. Proc Natl Acad Sci U S A 1999;96:11452-7.

54. Forbes E, Hulett M, Ahrens R, et al. ICAM-1-dependent pathways regulate colonic eosinophilic inflammation. J Leukoc Biol 2006;80: 330-41.

55. Bochner BS, Schleimer RP. Mast cells, basophils, and eosinophils: distinct but overlapping pathways for recruitment. Immunol Rev 2001;179:5-15.

56. Gleich GJ. Mechanisms of eosinophil-associated inflammation. J Allergy Clin Immunol 2000;105:651-63.

57. Mishra A, Hogan SP, Brandt EB, et al. Enterocyte expression of the eotaxin and interleukin-5 transgenes induces compartmentalized dysregulation of eosinophil trafficking. J Biol Chem 2002;277:4406-12.

58. Kunkel EJ, Campbell JJ, Haraldsen G, et al. Lymphocyte CC chemokine receptor 9 and epithelial thymus-expressed chemokine (TECK) expression distinguish the small intestinal immune compartment: epithelial expression of tissue-specific chemokines as an organizing principle in regional immunity. J Exp Med 2000;192:761-8.

59. Jung YJ, Woo SY, Jang MH, et al. Human eosinophils show chemotaxis to lymphoid chemokines and exhibit antigen-presenting-cell-like properties upon stimulation with IFN-gamma, IL-3 and GM-CSF. Int Arch Allergy Immunol 2008;146:227-34.

60. Liu LY, Jarjour NN, Busse WW, et al. Chemokine receptor expression on human eosinophils from peripheral blood and bronchoalveolar lavage fluid after segmental antigen challenge. J Allergy Clin Immunol 2003;112:556-62.
61. Georas SN, McIntyre BW, Ebisawa M, et al. Expression of a functional laminin receptor (alpha 6 beta 1, very late activation antigen-6) on human eosinophils. Blood 1993;82:2872-9.

62. Tourkin A, Anderson T, LeRoy EC, et al. Eosinophil adhesion and maturation is modulated by laminin. Cell Adhes Commun 1993;1:16176.

63. Ngo P, Furuta GT, Antonioli DA, et al. Eosinophils in the esophaguspeptic or allergic eosinophilic esophagitis? Case series of three patients with esophageal eosinophilia. Am J Gastroenterol 2006;101: $1666-70$.

64. Rodrigo S, Abboud G, Oh D, et al. High intraepithelial eosinophil counts in esophageal squamous epithelium are not specific for eosinophilic esophagitis in adults. Am J Gastroenterol 2008;103:435-42.

65. Furuta GT, Liacouras CA, Collins MH, et al. Eosinophilic esophagitis in children and adults: a systematic review and consensus recommendations for diagnosis and treatment. Gastroenterology 2007;133: 1342-63.

66. Blanchard C, Wang N, Stringer KF, et al. Eotaxin-3 and a uniquely conserved gene-expression profile in eosinophilic esophagitis. J Clin Invest 2006;116:536-47.

67. Blanchard C, Mingler MK, Vicario M, et al. IL-13 involvement in eosinophilic esophagitis: transcriptome analysis and reversibility with glucocorticoids. J Allergy Clin Immunol 2007;120:1292-300.

68. Rothenberg ME, Spergel JM, Sherrill JD, et al. Common variants at 5 q22 associate with pediatric eosinophilic esophagitis. Nat Genet 2010;42:289-91.

69. Mishra A, Hogan SP, Brandt EB, et al. An etiological role for aeroallergens and eosinophils in experimental esophagitis. J Clin Invest 2001;107:83-90.

70. Akei HS, Mishra A, Blanchard C, et al. Epicutaneous antigen exposure primes for experimental eosinophilic esophagitis in mice. Gastroenterology 2005;129:985-94.

71. Mishra A, Rothenberg ME. Intratracheal IL-13 induces eosinophilic esophagitis by an IL-5, eotaxin-1, and STAT6-dependent mechanism. Gastroenterology 2003;125:1419-27.

72. Blanchard C, Mishra A, Saito-Akei H, et al. Inhibition of human interleukin-13-induced respiratory and oesophageal inflammation by anti-human-interleukin-13 antibody (CAT-354). Clin Exp Allergy 2005;35:1096-103.

73. Rayapudi M, Mavi P, Zhu X, et al. Indoor insect allergens are potent inducers of experimental eosinophilic esophagitis in mice. J Leukoc Biol 2010;88:337-46.

74. Stein ML, Collins MH, Villanueva JM, et al. Anti-IL-5 (mepolizumab) therapy for eosinophilic esophagitis. J Allergy Clin Immunol 2006; 118:1312-9.

75. Straumann A, Conus S, Grzonka P, et al. Anti-interleukin-5 antibody treatment (mepolizumab) in active eosinophilic oesophagitis: a randomised, placebo-controlled, double-blind trial. Gut 2010;59:21-30.

76. Hogan SP, Mishra A, Brandt EB, et al. A pathological function for eotaxin and eosinophils in eosinophilic gastrointestinal inflammation. Nat Immunol 2001;2:353-60.

77. Lee JJ, Lee NA. Eosinophil degranulation: an evolutionary vestige or a universally destructive effector function? Clin Exp Allergy 2005;35: 986-94.

78. Kierszenbaum F, Ackerman SJ, Gleich GJ. Destruction of bloodstream forms of Trypanosoma cruzi by eosinophil granule major basic protein. Am J Trop Med Hyg 1981;30:775-9.

79. Behm CA, Ovington KS. The role of eosinophils in parasitic helminth infections: insights from genetically modified mice. Parasitol Today 2000;16:202-9.

80. Klion AD, Nutman TB. The role of eosinophils in host defense against helminth parasites. J Allergy Clin Immunol 2004;113:30-7.

81. Herndon FJ, Kayes SG. Depletion of eosinophils by anti-IL-5 monoclonal antibody treatment of mice infected with Trichinella spiralis does not alter parasite burden or immunologic resistance to reinfection. J Immunol 1992;149:3642-7.

82. Hokibara S, Takamoto M, Tominaga A, et al. Marked eosinophilia in interleukin-5 transgenic mice fails to prevent Trichinella spiralis infection. J Parasitol 1997;83:1186-9.

83. Lotfi R, Lee JJ, Lotze MT. Eosinophilic granulocytes and damageassociated molecular pattern molecules (DAMPs): role in the inflammatory response within tumors. J Immunother 2007;30:16-28. 
84. Tepper RI, Pattengale PK, Leder P. Murine interleukin-4 displays potent anti-tumor activity in vivo. Cell 1989;57:503-12.

85. Mattes J, Hulett M, Xie W, et al. Immunotherapy of cytotoxic T cellresistant tumors by Thelper 2 cells: an eotaxin and STAT6-dependent process. J Exp Med 2003;197:387-93.

86. Simson L, Ellyard JI, Dent LA, et al. Regulation of carcinogenesis by IL-5 and CCL11: a potential role for eosinophils in tumor immune surveillance. J Immunol 2007;178:4222-9.

87. Wong DT, Bowen SM, Elovic A, et al. Eosinophil ablation and tumor development. Oral Oncol 1999;35:496-501.

88. Gleich GJ, Loegering DA, Bell MP, et al. Biochemical and functional similarities between human eosinophil-derived neurotoxin and eosinophil cationic protein: homology with ribonuclease. Proc Natl Acad Sci U S A 1986;83:3146-50.

89. Månsson A, Cardell LO. Role of atopic status in Toll-like receptor (TLR)7- and TLR9-mediated activation of human eosinophils. J Leukoc Biol 2009;85:719-27.

90. Månsson A, Fransson M, Adner M, et al. TLR3 in human eosinophils: functional effects and decreased expression during allergic rhinitis. Int Arch Allergy Immunol 2010;151:118-28.

91. Lehrer RI, Szklarek D, Barton A, et al. Antibacterial properties of eosinophil major basic protein and eosinophil cationic protein. J Immunol 1989;142:4428-34.

92. Linch SN, Kelly AM, Danielson ET, et al. Mouse eosinophils possess potent antibacterial properties in vivo. Infect Immun 2009;77:497682.

93. Yousefi S, Gold JA, Andina N, et al. Catapult-like release of mitochondrial DNA by eosinophils contributes to antibacterial defense. Nat Med 2008;14:949-53.

94. Beeson PB, Bass DA. The eosinophil. Major Probl Intern Med 1977; $14: 1-269$.

95. Wang HB, Ghiran I, Matthaei K, et al. Airway eosinophils: allergic inflammation recruited professional antigen-presenting cells. J Іттиnol 2007; 179:7585-92.

96. Shi HZ, Humbles A, Gerard C, et al. Lymph node trafficking and antigen presentation by endobronchial eosinophils. J Clin Invest 2000; 105:945-53.

97. Burgel PR, Lazarus SC, Tam DC, et al. Human eosinophils induce mucin production in airway epithelial cells via epidermal growth factor receptor activation. J Immunol 2001;167:5948-54.

98. Ding GQ, Zheng CQ, Bagga SS. Up-regulation of the mucosal epidermal growth factor receptor gene in chronic rhinosinusitis and nasal polyposis. Arch Otolaryngol Head Neck Surg 2007;133:1097103.

99. Shen HH, Xu F, Zhang GS, et al. CCR3 monoclonal antibody inhibits airway eosinophilic inflammation and mucus overproduction in a mouse model of asthma. Acta Pharmacol Sin 2006;27:1594-9.

100. Hur GY, Lee SY, Lee SH, et al. Potential use of an anticancer drug gefinitib, an EGFR inhibitor, on allergic airway inflammation. Exp Mol Med 2007;39:367-75.

101. Rothenberg ME. Eosinophilia. N Engl J Med 1998;338:1592-600.

102. Choe MM, Sporn PH, Swartz MA. An in vitro airway wall model of remodeling. Am J Physiol Lung Cell Mol Physiol 2003;285:L42733.

103. Pegorier S, Wagner LA, Gleich GJ, et al. Eosinophil-derived cationic proteins activate the synthesis of remodeling factors by airway epithelial cells. J Immunol 2006;177:4861-9.

104. Lee JJ, Dimina D, Macias MP, et al. Defining a link with asthma in mice congenitally deficient in eosinophils. Science 2004;305:1773-6.

105. Straumann A, Rossi L, Simon HU, et al. Fragility of the esophageal mucosa: a pathognomonic endoscopic sign of primary eosinophilic esophagitis? Gastrointest Endosc 2003;57:407-12.

106. Costello RW, Schofield BH, Kephart GM, et al. Localization of eosinophils to airway nerves and effect on neuronal M2 muscarinic receptor function. Am J Physiol 1997;273:L93-103.

107. Dvorak AM, Onderdonk AB, McLeod RS, et al. Ultrastructural identification of exocytosis of granules from human gut eosinophils in vivo. Int Arch Allergy Immunol 1993;102:33-45.

108. Kingham PJ, McLean WG, Walsh MT, et al. Effects of eosinophils on nerve cell morphology and development: the role of reactive oxygen species and p38 MAP kinase. Am J Physiol Lung Cell Mol Physiol 2003;285:L915-24.
109. Durcan N, Costello RW, McLean WG, et al. Eosinophil-mediated cholinergic nerve remodeling. Am J Respir Cell Mol Biol 2006;34: $775-86$.

110. Raap U, Wardlaw AJ. A new paradigm of eosinophil granulocytes: neuroimmune interactions. Exp Dermatol 2008;17:731-8.

111. Zheutlin LM, Ackerman SJ, Gleich GJ, et al. Stimulation of basophil and rat mast cell histamine release by eosinophil granule-derived cationic proteins. J Immunol 1984;133:2180-5.

112. Furuta GT, Ackerman SJ, Lu L, et al. Stem cell factor influences mast cell mediator release in response to eosinophil-derived granule major basic protein. Blood 1998;92:1055-61.

113. Okayama Y, el-Lati SG, Leiferman KM, et al. Eosinophil granule proteins inhibit substance P-induced histamine release from human skin mast cells. J Allergy Clin Immunol 1994;93:900-9.

114. Boddington MM, Truelove SC. Abnormal epithelial cells in ulcerative colitis. Br Med J 1956;1:1318-21.

115. Bercovitz ZT, Sommers SC. Altered inflammatory reaction in nonspecific ulcerative colitis. Arch Intern Med 1966;117: $504-10$.

116. Truelove SC, Richards WC. Biopsy studies in ulcerative colitis. $\mathrm{Br}$ Med J 1956;1:1315-8.

117. Wright R, Truelove SC. Circulating and tissue eosinophils in ulcerative colitis. Am J Dig Dis 1966;11:831-46.

118. Rowe AH. Chronic ulcerative colitis, an allergic disease. Ann Allergy 1949;7:727-51.

119. DeBrosse CW, Case JW, Putnam PE, et al. Quantity and distribution of eosinophils in the gastrointestinal tract of children. Pediatr Dev Pathol 2006:9:210-8.

120. Wedemeyer J, Vosskuhl K. Role of gastrointestinal eosinophils in inflammatory bowel disease and intestinal tumours. Best Pract Res Clin Gastroenterol 2008;22:537-49.

121. Protheroe C, Woodruff SA, de Petris G, et al. A novel histologic scoring system to evaluate mucosal biopsies from patients with eosinophilic esophagitis. Clin Gastroenterol Hepatol 2009;7:74955. e11.

122. Pensabene L, Brundler MA, Bank JM, et al. Evaluation of mucosal eosinophils in the pediatric colon. Dig Dis Sci 2005;50: 221-9.

123. Luck W, Becker M, Niggemann B, et al. In vitro release of eosinophil cationic protein from peripheral eosinophils reflects disease activity in childhood Crohn disease and ulcerative colitis. Eur J Pediatr 1997; $156: 921-4$

124. Dvorak AM, Osage JE, Monahan RA, et al. Crohn's disease: transmission electron microscopic studies. III. Target tissues. Proliferation of and injury to smooth muscle and the autonomic nervous system. Hum Pathol 1980;11:620-34.

125. Carvalho AT, Elia CC, de Souza HS, et al. Immunohistochemical study of intestinal eosinophils in inflammatory bowel disease. J Clin Gastroenterol 2003;36:120-5.

126. Bischoff SC, Mayer J, Nguyen QT, et al. Immunnohistological assessment of intestinal eosinophil activation in patients with eosinophilic gastroenteritis and inflammatory bowel disease. Am J Gastroenterol 1999;94:3521-9.

127. Dubucquoi S, Janin A, Klein O, et al. Activated eosinophils and interleukin 5 expression in early recurrence of Crohn's disease. Gut 1995;37:242-6.

128. Berstad A, Borkje B, Riedel B, et al. Increased fecal eosinophil cationic protein in inflammatory bowel disease. Hepatogastroenterology 1993;40:276-8.

129. Bischoff SC, Grabowsky J, Manns MP. Quantification of inflammatory mediators in stool samples of patients with inflammatory bowel disorders and controls. Dig Dis Sci 1997;42:394-403.

130. Saitoh O, Kojima K, Sugi K, et al. Fecal eosinophil granule-derived proteins reflect disease activity in inflammatory bowel disease. Am J Gastroenterol 1999;94:3513-20.

131. Peterson CG, Sangfelt P, Wagner M, et al. Fecal levels of leukocyte markers reflect disease activity in patients with ulcerative colitis. Scand J Clin Lab Invest 2007;67:810-20.

132. Carlson M, Raab Y, Peterson C, et al. Increased intraluminal release of eosinophil granule proteins EPO, ECP, EPX, and cytokines in ulcerative colitis and proctitis in segmental perfusion. Am J Gastroenterol 1999;94:1876-83. 
133. Troncone R, Caputo N, Esposito V, et al. Increased concentrations of eosinophilic cationic protein in whole-gut lavage fluid from children with inflammatory bowel disease. J Pediatr Gastroenterol Nutr 1999;28:164-8.

134. Raab Y, Fredens K, Gerdin B, et al. Eosinophil activation in ulcerative colitis: studies on mucosal release and localization of eosinophil granule constituents. Dig Dis Sci 1998;43:1061-70.

135. Heatley RV, James PD. Eosinophils in the rectal mucosa. A simple method of predicting the outcome of ulcerative proctocolitis? Gut 1979;20:787-91.

136. Raab Y, Sundberg C, Hallgren R, et al. Mucosal synthesis and release of prostaglandin E2 from activated eosinophils and macrophages in ulcerative colitis. Am J Gastroenterol 1995;90:614-20.

137. Wallace JL. Prostaglandin biology in inflammatory bowel disease. Gastroenterol Clin North Am 2001;30:971-80.

138. Ahrens R, Waddell A, Seidu L, et al. Intestinal macrophage/epithelial cell-derived CCL11/eotaxin-1 mediates eosinophil recruitment and function in pediatric ulcerative colitis. J Immunol 2008;181:7390-9.
139. Furuta GT, Nieuwenhuis EE, Karhausen J, et al. Eosinophils alter colonic epithelial barrier function: role for major basic protein. Am J Physiol Gastrointest Liver Physiol 2005;289:G890-7.

140. Coppi LC, Thomazzi SM, de Ayrizono ML, et al. Comparative study of eosinophil chemotaxis, adhesion, and degranulation in vitro in ulcerative colitis and Crohn's disease. Inflamm Bowel Dis 2007;13:211-8.

141. Forbes E, Murase T, Yang M, et al. Immunopathogenesis of experimental ulcerative colitis is mediated by eosinophil peroxidase. J Immunol 2004;172:5664-75.

142. Shichijo K, Makiyama K, Wen CY, et al. Antibody to eosinophil cationic protein suppresses dextran sulfate sodium-induced colitis in rats. World J Gastroenterol 2005;11:4505-10.

143. Vieira AT, Fagundes CT, Alessandri AL, et al. Treatment with a novel chemokine-binding protein or eosinophil lineage-ablation protects mice from experimental colitis. Am J Pathol 2009;175:2382-91.

144. Takedatsu H, Mitsuyama K, Matsumoto S, et al. Interleukin-5 participates in the pathogenesis of ileitis in SAMP1/Yit mice. Eur $J$ Immunol 2004;34:1561-9. 